\title{
Relationship between phosphorus fractions of some selected Sudanese soil orders to phosphate availability
}

\author{
Abdel Wahab Ahmed Mohamed Ahmed, Mohammed Abdalla Elsheikh *, \\ Yousif El Gorashi El Mahi
}

Department of Soil and Environment Sciences, Faculty of Agriculture, University of Khartoum Shambat, Sudan

\begin{abstract}
A laboratory experiment was conducted to determine the extent and the importance of phosphorus (P) fractions of some agriculturally important Sudanese soils on P availability. The soils were gathered from different locations in Sudan, to represent three different orders: Aridisols (Um Dum soil, North Kordofan state), Alfisols (Hagu soil, Senar state), and Vertisols (Hosh soil, Gezira state). The soil P was fractionated using an authenticated procedure. The results showed that the soils had low total, organic and available $P$ contents. Most of the inorganic soil P was present in the Fe-Al fraction in Um Dum soil ( $>$ $50 \%$ ), and about $40 \%$ of this fraction in Hagu soil, but, only $20 \%$ in alkaline Hosh soil. The Ca-P fraction constituted $>60 \%$ in Hosh soil, about $40 \%$ in Hagu soil and $20 \%$ in Um Dum soil. The available $\mathrm{P}$ in the top soils studied was positively related to the percent sum of $\mathrm{Al}+\mathrm{Fe}-\mathrm{P}$ of the total $\mathrm{P}$, and was negatively related to the percent $\mathrm{Ca}-\mathrm{P}$ fraction content of the total P. It has been proposed that the P sorption starts by exchange with singly coordinate $\mathrm{Fe}$ or $\mathrm{Al}-\mathrm{OH}$ clay $\left(\mathrm{OH}^{-}\right.$edge group) and quickly reorganizes into more stable and less soluble ring forms especially at $\mathrm{pH}$ more than 7.0, Alkaline $\mathrm{pH}$ more than 8.0 in soil like Hosh, will in presence of $\mathrm{Ca}$, favour with time, the formation of inactive less soluble form like octacalcium phosphates and apatites at expense of the initial $\mathrm{Al}$ and Fe-P forms which are less stable at alkaline $\mathrm{pH}$.
\end{abstract}

\section{Article Info}

Received : 26.02 .2018

Accepted : 30.04.2018

Keywords: Phosphorus forms, total phosphorus, organic phosphorus, inorganic phosphorus, available soil phosphorus, Sudanese soils.

(C) 2018 Federation of Eurasian Soil Science Societies. All rights reserved

\section{Introduction}

Phosphorus is an important element for all living organisms and, second to nitrogen as a limiting factor in plant growth and production (Arai and Sparks, 2007). The main P source is phosphate rocks, which are nonrenewable. Consequently, it is high time to undertake new strategies to use $\mathrm{P}$ efficiently to conserve available $\mathrm{P}$ in soil. There are many factors that contribute to make plant available $\mathrm{P}$ below demand for optimum crops production such as very low total $\mathrm{P}$ in soil, the human activities causing imbalance between inputs and outputs of $\mathrm{P}$ nutrient in soil, precipitation of $\mathrm{P}$ with calcium (Ca), iron ( $\mathrm{Fe}$ ), and aluminum ( $\mathrm{Al}$ ), and adsorption of P in soil (Hunt et al., 2007; Melese et al., 2015). These factors become serious, especially in soils of inherently low P status. The Sudanese soils, similar to many agricultural soils of the world, are generally deficient in the amount of soil P. Although, several authors have reported independently that Sudanese agricultural soils are deficient in P, fertilizer experiments, conducted under Sudan soil condition, have shown erratic response of crops to the application of P, with few exceptions (Elsheikh et al., 2007; Abuswar and Omer, 2011). Plants take up P from the soil solution, which is replenished by various insoluble

\footnotetext{
${ }^{*}$ Corresponding author.

Department of Soil and Environment Sciences, Faculty of Agriculture, University of Khartoum Shambat, Khartoum North 13314 Sudan

Tel.: +249 907199250

E-mail address: mohmedelsheikh@gmail.com

e-ISSN: 2147-4249 DOI: $10.18393 /$ ejss.421609
} 
P pools in the soil (Mengel and Kirkby, 2001). Thus, knowledge and information about the different P pools are useful parameters to assessing $\mathrm{P}$ available to plant and can be helpful to provide proper management of fertilizer, leading to increase in P use-efficiency in in the soil-plant system (Mostashari et al., 2008; Halajnia et al., 2009). Extensive research has been conducted on the subject worldwide, whereas, there is a paucity of studies on P status of most tropical soils and indeed Sudanese soils. Therefore, the objective of this research was to characterize the extent of $\mathrm{P}$ in different $\mathrm{P}$ fractions of some major Sudanese soil orders and their impact on P availability.

\section{Material and Methods}

\section{Soil materials}

The study was conducted on three Sudanese soils, gathered from different locations that represent the main dominant soil orders, having different physical and chemical characteristics. These soils belong to three major orders: Aridisols (Um Dum soil, North Kordofan state), Alfisols (Hagu soil, Senar state), and Vertisols (Hosh soil, Gezira state). Some physical and chemical properties of these soils were presented in Table1. Particle size distribution was measured by pipette international method. Other soil properties were determined according to the procedures of Estefan et al. (2013).

Table 1. Characteristics of three Sudanese soils studied

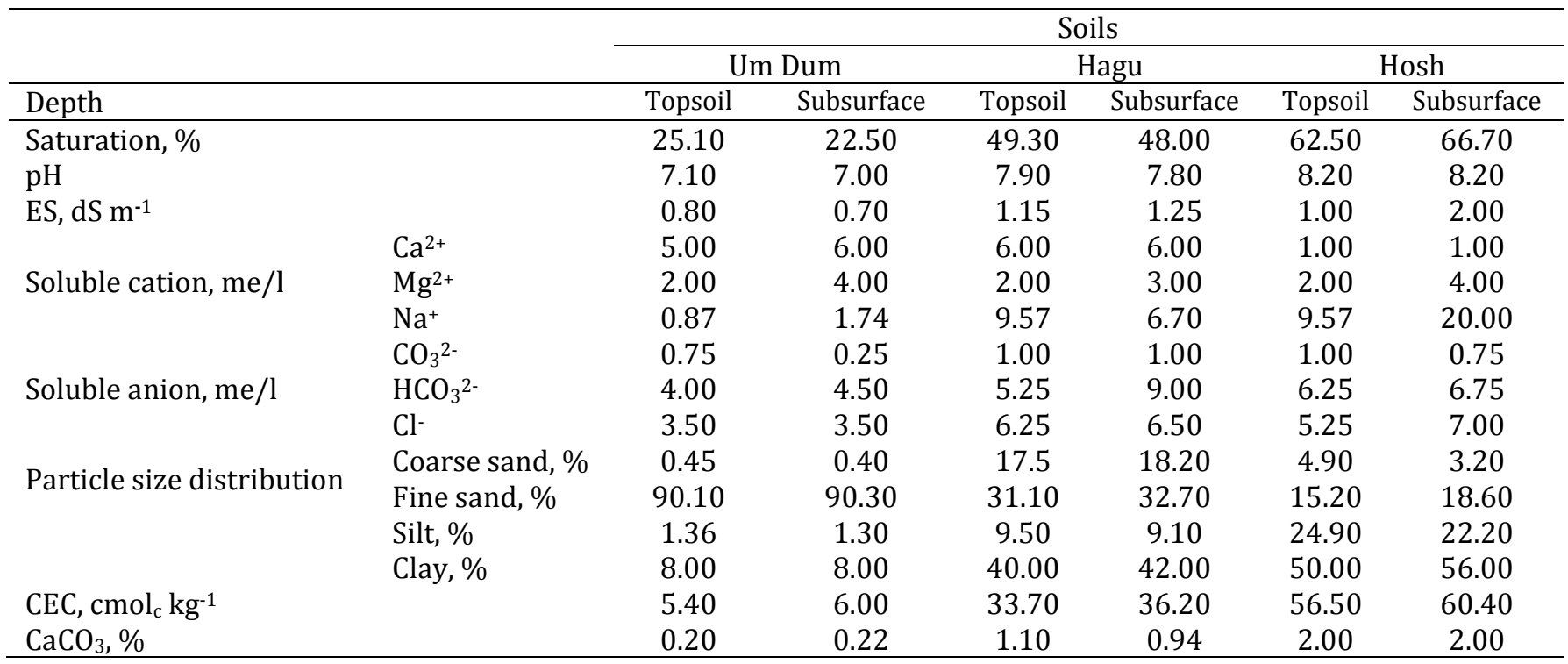

\section{Phosphorus fraction}

The procedure of Chang and Jackson (1957) as modified by Petersen and Corey (1966) was used for determination of different forms of phosphorus. Saloid $\mathrm{P}$ was extracted by $\mathrm{NH}_{4} \mathrm{Cl}$ and $\mathrm{Al}-\mathrm{P}$ by $0.5 \mathrm{M} \mathrm{NH} \mathrm{N}_{4} \mathrm{~F}$. The letter was followed by extraction of Fe-P using $0.1 \mathrm{M} \mathrm{NaOH}$, saturated $\mathrm{NaCl}$ plus a few drops of concentrated $\mathrm{H}_{2} \mathrm{SO}_{4}$. Occluded $\mathrm{P}$ was extracted by $0.1 \mathrm{M} \mathrm{NaOH}$ and Ca-P by $0.25 \mathrm{M} \mathrm{H}_{2} \mathrm{SO}_{4}$. Residual P was extracted by a mixture of $\mathrm{HNO}_{3}, \mathrm{HCl}$ and $\mathrm{H}_{2} \mathrm{O}$. Organic $\mathrm{P}$ was determined by the ignition method of Legg and Black (1955). Reductant soluble $\mathrm{P}$ was estimated as the difference between total $\mathrm{P}$ and the sum of the organic $\mathrm{P}$ and inorganic $\mathrm{P}$ fractions. Available soil phosphorus was extracted by $\mathrm{NaHCO}_{3}$ according to the procedures of (Olsen et al., 1954).

\section{Results and Discussion}

\section{Total P}

The surface soils under study varied in their total P amounts, which were: 537.0, 299.0 and $165.0 \mathrm{mg} \mathrm{kg}^{-1}$, for Hosh, Hago and Um Dum respectively; the amount of subsurface P were 595.5, 279.5 and $169.0 \mathrm{mg} \mathrm{kg}^{-1}$ (Table 2). The soils under study could be classified according to their total P concentrations: Hosh $>$ Hago $>$ Um Dum, similar to order of percentage clay contents. The total phosphorus contents of normal soils vary from 100 to $2000 \mathrm{mg} \mathrm{kg}^{-1}$ (Kabata-Pendias and Pendias, 1992). The studied soils can be classified according to Tripathi et al., (1970) as low in P $\left(<600 \mathrm{mg} \mathrm{kg}^{-1}\right)$. Because total P is an inherent property of soils, the generally low total $\mathrm{P}$ values in studied soils could be related to the nature of the parent material. Soil $\mathrm{P}$ occurs in inorganic and organic forms and their relative distribution varies with climate, vegetation, parent material and soil management practices. 
Table 2. Total, organic, inorganic and $\mathrm{NaHCO}_{3}$ extractable phosphorus

\begin{tabular}{lcccccccc}
\hline \multirow{2}{*}{ Soil } & \multicolumn{2}{c}{ Total } & \multicolumn{2}{c}{ Organic } & \multicolumn{2}{c}{ Inorganic } & \multicolumn{2}{c}{ NaHCO $_{3}$ extractable P } \\
\cline { 2 - 8 } & Topsoil & Subsurface & Topsoil & Subsurface & Topsoil & Subsurface & Topsoil & Subsurface \\
\hline Um Dum & 165.00 & 169.00 & 9.50 & 7.25 & 155.50 & 161.75 & 5.30 & 3.10 \\
Hagu & 299.00 & 279.50 & 38.25 & 37.50 & 260.75 & 242.00 & 3.25 & 3.50 \\
Hosh & 537.00 & 595.50 & 30.00 & 27.00 & 507.00 & 568.50 & 2.50 & 2.75 \\
\hline
\end{tabular}

\section{Organic P}

As shown in Table 2 the organic P for Um Dum soil are 9.5 and 7.5, for Hago soil are 38.3 and 37.5, whereas, for Hosh soil are 37.5 and $27.0 \mathrm{mg} \mathrm{kg}^{-1}$ for the top soil and subsurface, respectively. This amount consists of $5.6 \%-4.4 \%, 12.8 \%-13.4 \%$ and $5.6 \%-4.5 \%$ of the total P of Um Dum, Hago and Hosh for the top and subsurface soil, respectively. The three soils were low in soil organic $\mathrm{P}$ values and these findings were expected as the organic matter is very low. In general, organic P content decreased with depth, as shown in Table 2. Under tropical conditions, organic P is readily mineralized into inorganic P (Tisdale and Nelson, 1995) and can thus be an important additional P source to plants.

\section{Inorganic $\mathbf{P}$}

The amounts of inorganic $P$ for top soil and subsurface were 155.5-161.7, 260.7-242.0 and 507.0-568.0 mg $\mathrm{kg}^{-1}$ for Um Dum, Hago, and Hosh, respectively (Table 2). This amount consists of 93.8-95.7, 87.2-86.6 and 94.4-95.5 percent of total P for top and subsurface soils for Um Dum, Hago and Hosh, respectively. According to Thomas and Peaslee (1973) there are three forms of inorganic P, the first is most available (precipitated) or chemisorbed on surface, and the second is somewhat available discrete particle (Ca-P, Al-P, $\mathrm{Fe}-\mathrm{P}$ and $\mathrm{Fe}, \mathrm{Al}-\mathrm{P}$ ) and the third is little available (occluded $\mathrm{Ca}-\mathrm{P}$ in $\mathrm{CaCO}_{3}$ or silica, occluded $\mathrm{Al}-\mathrm{P}$ and Fe-P in iron oxides and redundant soluble Fe P occluded in Fe Oxides).

The large amount of the second form of the somewhat available discrete particle inorganic $\mathrm{P}$ forms, is a sign of high chemical weathering of the soils (Chang and Jackson, 1957). The form is called by many workers including Thomas and Peaslee (1973) as the active P forms which is the major sources of available P. It amounts to 81.0, 80.0, and 87.0\% of total P of Um Dum, Hago, and Hosh, respectively, for topsoil, whereas it is $83.0,71.0$, and $87.0 \%$ for subsurface of the three soils, respectively. The somewhat available discrete particle, constituted to 87.0, 86.0, and $92.0 \%$ of the total inorganic $P$ in the three of top soils, respectively, whereas, it is about 87.0, 82.0, and $92.0 \%$ in sub-surface soil of the three soils, respectively. The somewhat available discrete particle P form, in Um Dum soil, in both top soil and subsurface soil was about $30 \%$ of total inorganic P, present as Fe-P, followed by Ca-P and then AI-P (Table 3). For both Hago and Hosh soils, most of inorganic $\mathrm{P}$ was present as Ca-P, followed by Fe-P, and then AI-P. Similar results were found (Uriyo and Kasseba, 1973; Udo and Ogunwale, 1977). Some of the inorganic P may be present in the lattices of silicate minerals and as inclusions in minerals, e.g., in quartz crystals (Black, 1968). The largest form of inorganic $P$ in Hosh soil may be predominantly some form of the mineral apatite, perhaps most commonly calcium hydroxy or fluorapatite (Larsen, 1967). This means that most of the soil P may be in an unavailable form which the plants cannot use. Only the somewhat available discrete particle is generally accepted to be the main source of available inorganic P for plants (Thomas and Peaslee, 1973). The content of the three somewhat available discrete particles $\mathrm{P}$ forms varied among soil orders, reflecting the effect of different climatic and geographical conditions in which they were formed.

Table 3. Phosphorus inorganic fractions of three Sudanese soils

\begin{tabular}{|c|c|c|c|c|c|c|}
\hline \multirow{3}{*}{ Parameters } & \multicolumn{6}{|c|}{ Soil } \\
\hline & \multicolumn{2}{|c|}{ Um Dum } & \multicolumn{2}{|c|}{ Hagu } & \multicolumn{2}{|c|}{ Hosh } \\
\hline & Topsoil & Subsurface & Topsoil & Subsurface & Topsoil & Subsurface \\
\hline Saloid P & 5.00 & 3.50 & 0.00 & 0.00 & 0.00 & 0.00 \\
\hline $\mathrm{Al}-\mathrm{P}$ & 35.00 & 30.00 & 49.25 & 43.75 & 45.50 & 61.25 \\
\hline Fe-P & 52.80 & 61.25 & 52.5 & 47.25 & 50.00 & 52.50 \\
\hline OcclFe-P & 8.00 & 9.00 & 20.00 & 20.00 & 19.00 & 21.00 \\
\hline OcclAl-P & 7.50 & 7.50 & 16.50 & 22.50 & 17.50 & 23.75 \\
\hline $\mathrm{Ca}-\mathrm{P}$ & 47.70 & 50.50 & 122.50 & 108.50 & 375.00 & 410.00 \\
\hline
\end{tabular}

Regarding the third form, the little available inorganic $\mathrm{P}$, the amount of the reductant-soluble $\mathrm{Fe}-\mathrm{P}$, for top soil and subsurface were found 8.0-9.0, 20.0-21.0, and 19.0-21.0 \% for Um Dum, Hago, and Hosh, respectively. In addition to this, the amount of occluded Al-P were 7.5- 7.5, $16.5-22.5$, and 17.5-23.8\% for Um Dum, Hago, and Hosh, respectively. The results clearly show that the occluded Fe and Al-P level were 
low. The reductant-soluble Fe-P is a semi active form which may be dissolved under anaerobic conditions. The occluded Fe-P and Al-P form, being inert to reactions with the soil solution is, therefore, of limited contribution as a source of plant available $P$.

\section{Available soil P}

Available P of Um Dum are 5.3 and 3.1 and for Hago 3.25 and 3.25, while in Hosh was 2.5, and $2.75 \mathrm{mg} \mathrm{kg}^{-1}$ for top and subsurface, respectively (Table 2). The soil available P, is low, indicating that the soils are infertile with respect to $\mathrm{P}$. This may be due to the high clay contents of the latter soils which cause high $\mathrm{P}$ fixation. Figure 1 shows that the available $P$ in top soils was positively correlated to the percent of sum of $(\mathrm{Al}-\mathrm{P}+\mathrm{Fe}-\mathrm{P})$ of the total $\mathrm{P}$, and was negatively related to the percent Ca-P fraction content of the total $\mathrm{P}$.

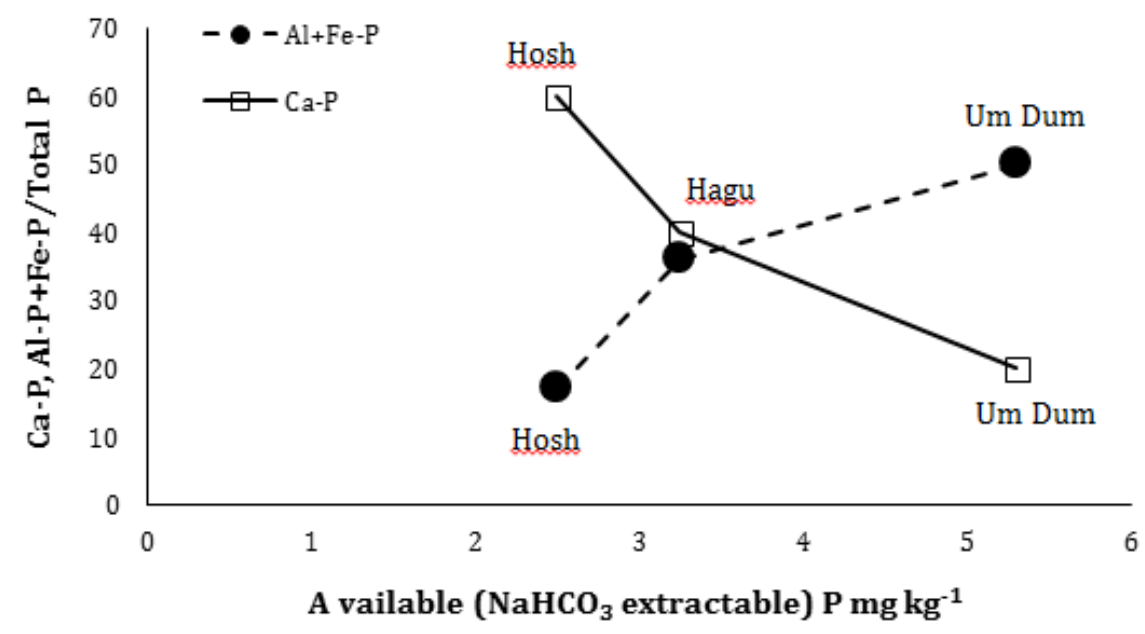

Figure 1. Relations between inorganic $\mathrm{P}$ fractions and available $\mathrm{P}$ in soils

\section{Effect of phosphorus fractions on phosphate availability}

Table 2 shows that the $\mathrm{NaHCO}_{3}$ extractable P was highest in the sandy Un Dum soils (5.3 mg kg-1) in top soil and 3.1 in the subsurface soil), very close to the amount of saloid P fraction (Table 3). It is noteworthy that Um Dum had the lowest active P fraction (Ca-P, Fe-P and Al-P) of the three soils studied. On the other hand, Hosh clay soil had the lowest $\mathrm{NaHCO}_{3}$ extractable $\mathrm{P}$, but the highest (523 mg kg-1) active $\mathrm{P}$, more than twice the active $\mathrm{P}$ of Um Dum, which was $240 \mathrm{mg} \mathrm{kg}^{-1}$. It seems that the difference in available $\mathrm{P}$ between the two soils is not related to the magnitude of the active $\mathrm{P}$, thought to be the source of available $\mathrm{P}$, but rather to the nature and properties of the of individual constituents of active P fraction. It is logical to propose that Hosh soil with $\mathrm{pH}=8.2$ will push its high Ca-P fraction faster towards more stable forms of low solubility than Um Dum $\mathrm{pH}=7.1$ (Lindsay and Moreno, 1960). Hosh Ca-P will more quickly ends up into sparingly soluble forms of apatite of very low activity. The third soil is Hagu of pH 7.9-7.8 may lie in between the two above mentioned soils.

It is relevant to note that despite the low $\mathrm{NaHCO}_{3}$ extractable $\mathrm{P}$ in central Sudan soils of 2-3 mg kg-1, many crops showed erratic response to P fertilization (Dawelbeit et al., 2010). The American Soil Science Society of Agronomy set a limit of $5 \mathrm{mg} \mathrm{kg}^{-1}$ between sufficiency and deficiency of soil P (Olsen and Sommers, 1982). It is known that the Sudan central clay plain soils originated from deposits carried by the Nile from Ethiopian high lands, having high rainfall and intensive vegetative cover. The soils there are organic, acidic and should fix considerable amount of $\mathrm{Fe}$ and $\mathrm{Al}$ phosphates. Particles of these phosphates which are transported by muddy waters of annual Nile floods are deposited on soil irrigation by Nile water of central clay plain fields (including Hosh). The Fe-Al phosphate particles will react with the alkaline central Sudan soils, producing sustained, but slow release of available P. Bohn et al. (1985) stated that both strengite and variscite would be good P fertilizer in basic soils.

$$
\begin{array}{ccccccc}
\mathrm{Fe}(\mathrm{OH})_{2} \mathrm{H}_{2} \mathrm{PO}_{4} & \text { or } & \mathrm{Al}(\mathrm{OH})_{2} \mathrm{H}_{2} \mathrm{PO}_{4} & \rightarrow & \mathrm{H}_{2} \mathrm{PO}_{4}^{-}+\mathrm{Fe}(\mathrm{OH})_{3} \downarrow & \text { or } & \mathrm{Al}(\mathrm{OH})_{3 \downarrow} \\
\text { strengite } & \text { or } & \text { variscite } & \rightarrow & \text { dihydrogen orthophosphate }+ \text { ferric hydroxide } \downarrow & \text { or } & \text { Alumuim hydroxide } \\
\downarrow
\end{array}
$$

Ahmed (1980) studied the fate of P applied to the alkaline Hosh and Hagu soil using conventional methods and radioactive ${ }^{22} \mathrm{P}$. He found that about $80 \%$ of the added $\mathrm{P}$ fertilizer was recovered after 12 months with Al-P fractions followed by Fe-P, but only about $6 \%$ were recovered in calcium form. However, P availability 
was not, governed by retained strengite and variscite, suggesting that the retained phosphate was present in forms less soluble than either of the two compounds Figure 2. Ahmed (1980) found that removal of sesquioxides from Hosh and Hagu soils slightly reduced the P adsorption maximum and concluded that most of the $\mathrm{P}$ adsorbed has been held by chemisorption $\mathrm{Al}$ and Fe clays edges. Ryden et al. (1974) suggested that phosphate first replaces singly coordinated $\mathrm{Al}$ or $\mathrm{Fe} \mathrm{OH}$ groups and then quickly reorganizes into very stable and less soluble binuclear bridge between cations. Presence of the available Ca faver the formation and accumulation of the most stable phosphate form at high $\mathrm{pH}$, hydroxyl apatites. This does not contradict with initial formation of $\mathrm{Al}$ and $\mathrm{Fe}$ phosphates as latter are soluble at high $\mathrm{pH}$ and will transform during long centuries of the soil genesis to the more stable and less soluble calcium phosphates observed today in alkaline soils.

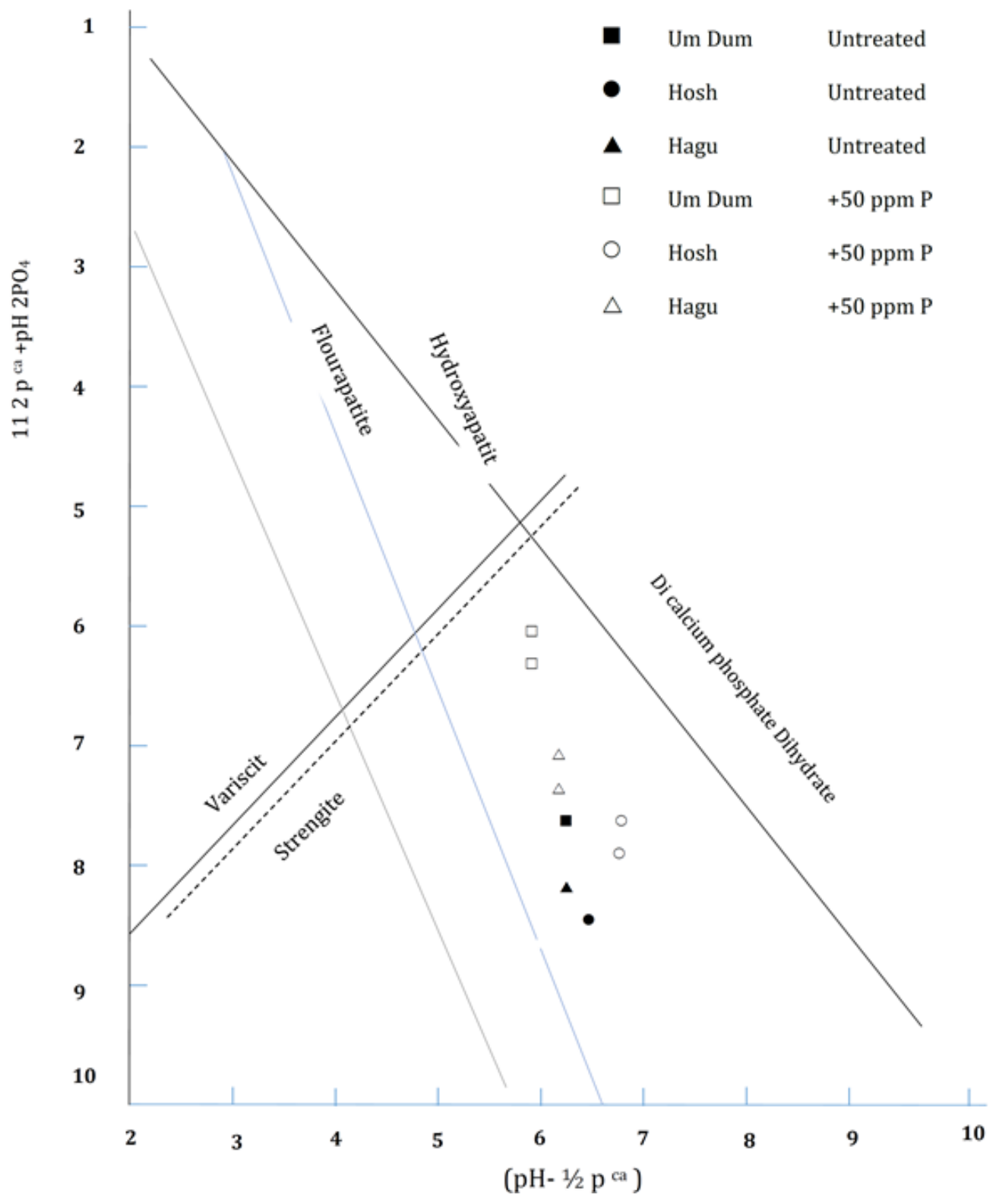

Figure 2. Solubility diagram for three soils

\section{Conclusion}

The study showed a wide range of differences in P status of major Sudanese soils orders. The three soils under study varied in the total $\mathrm{P}$ and were low in soil organic $\mathrm{P}$ values due to the very low organic matter content. Furthermore, the soil available $\mathrm{P}$ of above mentioned soils is low, indicating that the soils are infertile with respect to $\mathrm{P}$. Available $\mathrm{P}$ was directly proportional to Al-P fraction and was inversely proportional to the larger Ca $\mathrm{P}$ fraction in alkaline Hosh soil, indicating that $\mathrm{P}$ was present in inactive forms at high $\mathrm{pH}$. 


\section{References}

Abusuwar, A.O., Omer, E.A., 2011. Effect of intercropping, phosphorus fertilization and rhizobium inoculation on the growth and nodulation of some leguminous and cereal forages. Agriculture and Biology Journal of North America 2 (1): 109-124.

Ahmed, A.M., 1980. Studies on the native and applied phosphorus in some Sudan soils. M.Sc. Thesis. University of Khartoum, Faculty of Agriculture, Department Biochemistry and Soil Science, Khartoum, Sudan. 120p.

Arai, Y., Sparks, D.L., 2007. Phosphate reaction dynamics in soils and soil components: A multiscale approach. Advances in Agronomy 94: 135-179.

Bohn, H.L., McNeal, B.L., O'Connor, G.A., 1985. Soil Chemistry. Second edition. John Wiley \& Sons. New York, USA. 193p.

Chang, S. C., Jackson, M. L.,1957. Fractionation of soil phosphorus. Soil Science 84(2): 133-144.

Dawelbeit, S.E., Salih, F.M., Dahab, O.A., Ahmed, E.H., 2010. Status of fertilization and crop nutrition in irrigated agriculture in Sudan: Fertilizer use in Sudan. Research Findings: e-ifc No. 22, International Potash Institute. Available at [access date : 26.02.2018]: https://www.ipipotash.org/udocs/eifc_no22-rf1.pdf

Elsheikh, M.A., El-Tilib, A.M.A., Elsheikh, E.A.E., Awad El Karim, A.H., 2007. Effect of phosphate rock and triplesuperphosphate on growth and leaf N, P and K contents of groundnut (Arachis ltypogaea L.) grown on a clay soil. Arab University of Journal of Agricultural Science 15: 197-202.

Estefan, G., Sommer, R., Ryan, J., 2013. Methods of soil, plant, and water analysis: A manual for the West Asia and North Africa region. Third Edition. International Center for Agricultural Research in the Dry Areas (ICARDA), Beirut, Lebanon. 244p.

Halajnia, A., Haghnia, G.H., Fotovat, A., Khorasani, R., 2009. Phosphorus fractions in calcareous soils amended with P fertilizer and cattle manure. Geoderma 150(1-2): 209-213.

Hunt, J.F., Ohno, T., He, Z., Honeycutt, C.W., Dail, B.D., 2007. Inhibition of phosphorus sorption to goethite, gibbsite, and kaolin by fresh and decomposed organic matter. Biology Fertility Soils 44(2): 277-288.

Kabata-Pendias, A., Pendias, H., 1992 . Trace elements in soils and plants. Second edition. CRC Press, Boca Raton, Florida.USA. 365p.

Larsen, S., 1967. Soil phosphorus. Advance in Agronomy 19: 151-210.

Legg J.O., Black, C.A., 1955. Determination of organic phosphorus in soils: II. Ignition method. Soil Science Society of America Journal 19(2): 139-143.

Lindsay, W.l., Moreno, E.C., 1960. Phosphate phase equilibria in soils. Soil Science Society of America Journal 24(3): 177182.

Melese, A., Gebrekidan, H., Yli-Halla, M., Yitaferu, B., 2015. Phosphorus status, inorganic phosphorus forms, and physicochemical properties of acid soils of Farta District, Northwestern Highlands of Ethiopia. Applied and Environmental Soil Science Article ID 748390.

Mengel, K., Kirkby, E.A., 2001. Principles of plant nutrition. 5 $5^{\text {th }}$ edition. Kluwer Academic Publishers, Dordrecht, The Netherlands. 454p.

Mostashari, M., Muazardalan, M., Karimian, N., Hosseini, H.M., Rezai, H., 2008. Phosphorus fractions of selected calcareous soils of Qazvin province and their relationships with soil characteristics. American-Eurasian Journal Agricultural and Environmental Sciences 3(4): 547-553.

Olsen, S.R., Cole, C.V., Watanabe, F.S., Dean, L.A., 1954. Estimation of Available Phosphorus in Soils by Extraction with Sodium Bicarbonate. U. S. Department of Agriculture Circular No. 939.

Olsen, S.R., Sommers, L.E.,1982. Phosphorus. In: Methods of soil analysis. Part 2 Chemical and microbiological properties. 2nd edition. Page, A.L. (Ed.). American Society of Agronomy, No. 9, Madison, WI, USA. pp. 403-430.

Petersen, G.W., Corey, R.B., 1966. A Modified Chang and Jackson procedure for routine fractionation of inorganic soil phosphates. Soil Science Society of America Journal 30(5): 563-565.

Ryden, J.C., Syers, J.K., Harris, R.F., 1974. Phosphorus in runoff and streams. Advances in Agronomy 25:1-45.

Thomas, G.W., Peaslee, D.E., 1973. Testing soils for Phosphorus. In: Wash, L.M., Beaton, J.D., (eds.) Soil Testing and Plant Analysis. Soil Science Society of America, Madison, Wisconsin pp. 115-132

Tisdale, S.L., Nelson, W.L., Beaton, J.D., Halvin, J.L., 1995. Soil fertility and fertilizers. $5^{\text {th }}$ Edition. Macmillan Publishing Co., Inc. New York, USA. 634p.

Tripathi, B.R., Tandon, H.L.S., Tyner, E.H., 1970. Native inorganic phosphorus forms and their relation to some chemical indicies of phosphate availability for soils of Agra district. Soil Science 109(2): 93-101.

Udo, E.J., Ogunwale, J.A., 1977. Phosphorus fractions in selected Nigerian soils. Soil Science Society of America Journal 41(6): 1141-1146.

Uriyo, A.P., Kasseba, A., 1973. Phosphate fractions in some Tanzania soils. Geoderma 10(3): 181-192. 